\title{
Social and Governance Changes: Rate, Principles and Morals
}

\author{
Massimo N. Nardo \\ Ethos \& Dialogos Association, Italy \\ Ronald D. Francis \\ Victoria University, Australia
}

\begin{abstract}
This paper draws attention to two aspects of change; first, the rate of social change is a source of concern, to this is added that both the configuration of changes and the values dimension, add to those concerns. Change makes it hard to keep up, and is the generator of much stress. We need to apprehend that such a point applies strongly to all enterprises, in particular to governance issues. This article holds that the rate of change is compounded by a constantly changing configuration. To ameliorate those concerns it is held that there needs to be both an expression of agreed basic principles, and recognition that values are one of the most vital parts of that selection. In this the debate and explication of guiding principles, particularly in governance, that is crucial. The main point here is to again emphasise the complexity that results not only from the rate of change but also the configuration and moral values that it constantly tests. It is only by direct consideration that concern over such issues be reduced. It is also held that an explication of basic principles is a significant aid to coping with the source of such stress.
\end{abstract}

\section{Keywords}

Governance, Social change, Economics, Foundation of law, Complexity, Conceptualisation

\author{
Regulations are good \\ when they produce such a \\ by-product state, as to \\ make them virtually \\ redundant.
}

Carlo Donolo

\section{Introduction}

This work addresses the issue of social changes in the third millennium. It stemmed from a consideration of the notion of social change, and has particular application to business. In essence the

Copyright (C) 2013 Victoria University. This document has been published as part of the Journal of Business Systems, Governance and Ethics in both online and print formats. Educational and non-profit institutions are granted a nonexclusive licence to utilise this document in whole or in part for personal or classroom use without fee, provided that correct attribution and citation are made and this copyright statement is reproduced. Any other usage is prohibited without the express permission of the publisher. rate, rather than the fact, of change is distressing: second there is a pressing need to explicate the principles and values that are complex in that they involve moral values. In governance, as in society in general, changes such as recent and pressing issues result in new legislation, new requirements, new moral obligations, all of a rapidly changing nature. This article stemmed from the preparation of a MS by the first author: the mix of old and new problems 
engaging our concern, and showing the structural tensions inherent in such changes. The issue of the rate of change is addressed, and the point made that both the rate of change and the complications of principles and values complicate that analysis yet further. One of the most effective means of countering this problem is the working out, and the explication of such principles.

Just as the industrial revolution brought changes, so too does the pressure of present problems; such forces strain social stability, and require our urgent attention if we are to adapt. It is argued here that there are substantial changes, largely due to both changing circumstances and to the questioning of older beliefs. It is many years since 'future shock' was argued by Toffler in 1971. That thesis was that it was not that change takes place but, rather, that the rate of change is the source of concern. This argument applies with some force to corporate governance. The development of moral concern for the environment, the change from political dominion to corporate multinationals, and the use of limited liability are all examples of relatively recent developments.

To resolve such issues it is important that we develop guiding principles, based on up-to-date knowledge. This article attempts to extend that argument to include the configuration of problems, and to the extension of concerns that include strongly held values. Bouma (1998) examined the distinctions between institutions and organisations for the purposes of social change. His analysis bears upon this present one, but does not negate this present one: it simply adds to the complexity.

More recently the notion of future shock was given a cartographic and geopolitical connotation (Ferguson \& Mansbach, 2004). They argued that our mental maps of two-dimensional scale are inadequate to explain more recent events, and they document the view that identity is crucial to an understanding of contemporary events.

\section{Complexity}

Here we might compare the metaphors of the Ark and The Tower of Babel, recognising what is superfluous (and bound to lead to wreckage), and what to preserve. Such criteria help us to understand how we can simplify complexity, not to avoid mistakes but, rather, to avoid perishing. The Ark has a relatively simple structure that can defy the hostile elements: its essence is simplicity, with the richness of the world characterised by the representation of all living things as a potential. This minimalist approach represents a potential for re-creation. The complementary view is that of the Tower of Babel: one of a multiplicity of entities, of differences, and of seeming confusion. One prefers the simplicity, but must concede to complexity.

This complexity may be coped with by two means: firstly by simplifying, the most immediate reaction. In selecting from complexity you exclude those aspects deemed less relevant until you come to a lesser level of complexity that you can master. Then the question arises, what are you going to exclude? This principle finds expression in, for example, calls for the limiting of court trials. Because of the human limit on recall, and on understanding, one could envision a time when trials might be restricted to (say) a week for a murder trial or a complex commercial instance. The second method of coping is to provide 'order'; for example, put in a classification system, as did Linnaeus in biology. Ordering complexity is the root of the concept of system - one of the most powerful mental schemes in the history of human knowledge. For us to face successfully the challenge one may propose a path marked by several main steps:

1. The problems that affect human society in the present times are particularly vital. It is essential to solve them for society and, indeed, corporate governance, to survive. This requires paramount crucial choices - even though risky ones. How are we to choose?

2. Increasing complexity of the world we build up doesn't help. Complexity has become too big and thus we are in the need of simplifying. Such simplification should lead to decide priorities, and then reflected in essential principles. 
3. In making the choice we must take into account some constraints that derive from the very nature of the human beings and their social relationships.

4. As a result we may recognise the essential principles to be followed in order to choose.

\section{Contemporary problems}

Among the contemporary problems here are those of tyranny, climate change, ease of travel, the availability of social statistics, the imbalance of wealth, the press to emigration, and the questioning of established ideas. Here one should not underestimate the ease of communication and its consequences. The ready availability of information and ideas must be significant drivers of dissent, of migration, and of action to improve. The Arab Spring, the overthrow of such tyrants as those of Tunisia, Libya, and Egypt, together with the protests by the Kurds, the Tamils, and the Basques all point to an unwillingness to tolerate suppression of their aspirations. The dominance of the need for energy is an instance, recently addressed by Cottrell (2009). The general topic includes treating with oil-supplying nations, and the internationalisation of commerce, both being commercial instances.

The suppression of revolutionaries in Syria is a recent striking example. If one were to look to the improving side one would note a distinct unwillingness to tolerate such harshness and oppression. Second, one would be immensely cheered by the substantial reduction in violence - a point well documented by Pinker (2011). It may seem a strange conclusion to draw but the diminution of violence and the use of negotiation are becoming more prevalent. This applies strongly to governance issues wherein non-violent solutions are sought.

The need to address such issues as climate change, habitable countries, and corrupt political institutions is most pressing, and may be most readily addressed from a political perspective addressing the issues from a business point of view. Such a dire need requires precepts in place to guide a resolution. Two striking examples of guiding principles are the Doctrine of the 'separation of powers', and 'The rule of law'. Such bulwark's exploitation again needs to be kept firmly in mind, and constantly exercised.

\section{Conceptualisation}

Taking an example, that of climate change, one might consider the issues involved. First is the hard core evidence for climate change: second is the rate at which the debates change; third is the effect that it might have on our values, including the effect it will have on our children and grandchildren. One notes the change from 'global warming' to 'climate change': in this the views of sceptics must be considered, and their views accommodated. One cannot, and must not, dismiss critics as being destructive and wilfully ignorant. Further, business will to be cognisant of the issues, and do something about them as they are a serious cause of concern. In all of this we see that each individual will have a different constellation of concerns.

On that topic Lever-Tracy (2008) has argued that those not within environmental sociology have largely ignored the subject. She argued that there needs to be a fusion of interests, and substantial dialog, between sociology and the physical sciences in order for us not to ignore such a substantial point that will have a profound effect on our world outlook. In this the role of business is vital.

One of the obvious requirements here is to conceptualise the issues for discussion. Once such concepts and values are socially accepted they shape a dominant model, and the community develops a 'social pressure' to hold to it. The more the model is rooted in the social system, the stronger the pressure: it becomes easier to yield than to resist.

In order to 'explain' one must decide among different factors. It may be an economic one, a psychological one, a sociological one, or a moral one. One might ask, for example, why did Moses 
take 40 years to lead the Israelites out of bondage and into the Promised Land, a total distance of only a few hundred kilometres? On that information one would have to have him fail Navigation 101. Another way of looking at the Exodus is that Moses ensured that it was a different generation that left Egypt from the one that arrived in Palestine. The facts are the same, but the interpretation is different. How one decides between rival explanations is always problematical, and difficult to specify an overarching explanation .

One may look for theories that not only explain phenomena but also capture a point not commonly appreciated. For example, consequences are not always proportional to causes. The limits of rational analysis are evident in complexity. Our intellectual abilities are not sufficient to build up a complete mental model of every possible relationship between all entities. Quite recently the notion of the disproportion of causes and effects has been captured in Chaos Theory. The beating of the proverbial butterfly's wings in Brazil may cause a storm in Europe: Gavril Princip's assassination of the Archduke Ferdinand in Sarajevo meant that a bullet caused a world war and the loss of millions of lives. Chaos theory is a blend of mathematics, engineering, biology, and economics. As such it is an attempt to construct an overarching explanation. Thus the problem of making complexity comprehensible by conceptualising it: even though there is determinism that does not make issues predictable. For any system to operate it must be consistent of application. A possible solution rests on identifying essential principles suitable to uphold a fitting solution. Principles are stated below, which ensure the mechanisms to be simple and effective at once, the Consistency Principle representing the linkage between the sphere of moral values and practicality.

Issues that emerge here are shaped both by need, and by the will. Pressure from the system should be used in order to guide the community to implement and shelter its chosen values ('Systemic Design Principle'). A second instance is the Control Principle which entails the assignation of power to safeguard the observance of substantial ends, and which is reason for them to exist. In all of this it will be seen that the imperatives of power, of force, and of solidarity are essential for social functioning. It is essential that the social projects are based upon principles, whose observance appears both righteous to morality, and convenient to expediency. Making society, and its derivative business, work seems to be based upon principles, not all of which are articulated. Sometimes they seem to have elements of caprice, but still work. Indeed, one might argue that a deep discussion of political principles is an essential precursor to their adoption. One recalls Napoleon's precept 'I need lucky generals', just a businesses need 'lucky' guidance. Yet our effort must aim at selecting such principles, being grounded in human nature.

\section{The human sciences}

Human sciences, as distinct from the physical sciences, deal with phenomena that are meant to be relatively unfettered; ones in which there is a margin of choice. Thus human sciences include in their field not only the 'how', but also the 'why'. With the Theory of Gravity, nobody claims an explanation of its 'rationale' in order to believe it: its experimental authentication and its stability over time is sufficient. Dealing with human behaviour, however, is more complex: the perception of an underpinning 'freedom of acting' obliges to record 'tendencies' more than constant facts. An insight into motives is, here, critical to understanding. To that end these points are relevant:

1. A recognition, and a consequential diminution, of the distressing effect of the rate of change (the 'change principle').

2. The foundation of morality rests in abstaining from manipulating people and circumstances. The rule of law provides for autonomy, and manipulation is contrary to that (the 'autonomy principle'). 
3. Turning a benefit from the purpose for which it is granted is fraud: it eradicates the legitimacy of claim or action ('legitimacy and transparency principle').

4. Nobody may demand from the others a behaviour, which he himself refuses to take upon face to them (the 'reciprocity principle'). This ideal principle would see politicians who declare war to be among those first sent to the front: thus we recognise its limited application.

5. A social system, which wants to conform to given values, must shape interests, structures, and regulations according to these values (the 'consistency principle').

Although these principles may appear debatable, the solution given to the debate will definitely affect the sort of society we will have in place.

The structure of social relationships involves the basic tension between idealism and manipulation: it also involves a tension between idealism and pragmatism. Politics is often characterised by defining it as 'the art of the possible', and 'the art of compromise'. That tension sits uneasily with idealism. Indeed it is a basic dilemma for political parties who aspire to certain standards and goals, that their ability to achieve anything is compromised unless they yield.

\section{Personality, rewards and punishments - The human factor}

One of the clear findings from psychology is that reward is a more effective technique than is punishment. Having said that we have to recognise that sometimes punishment is necessary, as the criminal law clearly shows. Nevertheless, trying to proscribe phenomena, which are widespread and whose repression is probably bound to ultimately achieve no success, is often counter-productive. Its only effect will probably be fostering the growth of illegal markets and routes, as every example of prohibitionism made clear. Policing by law a behaviour that is rooted in personal choice, preference or values (as drinking or drugs or unusual sexual inclinations) has scant efficacy and makes doubtful sense. What we have to proscribe is rather the anti-social acts that may come from such behaviour (like violence, harassment, or the unwelcome and unjustified interference with the lives of others).

Enforcement is far less effective than is social control of the gentler kind. The pivotal mechanism of social control resides in the discipline of inter-private relationships: that is it resides in civil law. Multiplying coercive regulations only increases the complexity of the system. Attempts at evasion will inevitably arise. If elusive alternatives exist (and they usually do), the concerned party will eventually be able to find them. It is instructive to note that 'rewards' are critical to business. The 'reward' of customer needs, the 'rewards' of business returns, and the failure of unsuccessful businesses to 'reward' dissatisfied customers are obvious.

Success in achieving a goal rests essentially on the choice of suitable players. It is easier to train somebody in professional skills or techniques, than infuse in him or her moral traits like commitment, motivation, and values. However, under the same circumstances, learning techniques is easier than learning values. An example is school, which can, in due time, teach to virtually whomever, the ability of writing and reading - but it cannot necessarily transmit the values it preaches to the same extent. A business project is no exception. All of this is a plea for the selection process for all business and public offices to be mindful of social values - quite as important as technical competence.

Here it is appropriate to mention the selection of 'winners'. When an aspirant has been selected on the basis of previous experience that is no necessary guide to how they will perform in a new role. For example, a good manager might be promoted to a board. The fact that they were good at managing is no essential guide to seeing how competent they will be in an strategic role. Those who go after their goals regardless of the means will easily be short-term winners (and possibly abusers). 
One might ask is this an example of The Peter Principle (1969) wherein people are promoted beyond their level of competence?

One of the goals of social leadership is not simply to manage problems: the essential goal is to design a better structure able to benefit society. To imagine, and to design this structure, is one of the great challenges of our future. Perhaps the magnitude of the emergent problems confronting us is disheartening. Since there are no certain signals of impending collapse, one may be tempted to ignore the risk and to put off the remedies to the future. But this is a deceptive solution: when the signals become indisputably visible, it might be too late.

\section{Economics considerations}

While people are motivated by economic considerations, that is not the only consideration. The American presidential principle 'It's the economy, stupid' is relevant but not conclusive: economics is an important principle, but not the only one, and includes every additional labour, sacrifice, or indirect disadvantage (almost a plea for a Pigouvian tax) - taxing the cost of negative externalities, of the wider social costs, as one might tax the fast food outlets for the clean-up costs of discarded food containers. Society, it needs to be recalled, is a collective. It implies that whatever factors there are, each has wider implications. This also introduces the issue of co-operation. Co-operative people are a better choice than competitive people, rebuffing a myth of the present time. Competition is one means either of selection or of action, and is definitely functional to power: one must say, then, that cooperation, not competition, is to be preferred.

The Western world currently enjoys riches previously unimaginable: the problem here is the uneven distribution of wealth, readily measured by the Gini Index. People being what they are, immediate benefit so often takes a superior position to longer-term interests. The dominating peoples appear to care only about preserving the roots of their power. As if such privileges can widen endlessly without any corresponding imbalance, as if there were nobody else who is to pay the price. It seems, in other words, to be a zero-sum game rather than a win-win.

Forms of disparity other than economic ones are also apparent. For example, the pressure use of lobbyists by business to influence legislators; the lack of time to pursue goals other than immediate economic ones; and the failure of legislatures to represent certain interests of the constituency but, rather, following a party line. Such pressure groups may have an economic motivation: they may also have another wish. The example of the gun lobby in the USA is a prime example: their obsession with firearms is a source of both serious concern and of serious social consequences.

\section{Morals and logic}

Morals is the set of values commonly acknowledged by a social group, sometimes organised into a system. As such it is a complication in the system in that it developing values constantly interact with change. One of the difficulties here is that one might, in morals as in all else, use logic to draw conclusions - but from debateable premises. For a syllogistic example: The sphere is the perfect form, angels are perfect, therefore angels are spherical. Clearly one can only draw conclusions that are apt if both logic permits (validity), and that the premises are acceptable. One might, for example, hold that violence is wrong, but think it appropriate in bringing someone to justice. In business it is persuasion rather than force that is critical. Here the balance may be the injunction 'If force is necessary then use the minimum' - as one might in self-defence. Thus the principle is that the use of force is lawful only in defence, or in legal restoration: one respects the legally established limits. Problems will still be there: for example: should one intervene in the civil war of a neighbouring state in order to prevent (say) manslaughter or refugees streaming across the border? - and what is the position of profiting from sales to governments that deal with refugees?

A similar problem arises with the question of 'How should a government treat a minority group of shareholders who wish to change the board structure?' Even more complex is the issue of (say) 
tolerance. To be unduly tolerant might be to tolerate the intolerable, and thus destroy the very value that one wishes to preserve.

Here it becomes plain that morals, amongst other things, ascribe meaning to events. Instances are tested against values, and relevance ascribed to them. This aspect of meaning finds expression in various ways, including attachment to our children, our moral values, and our loyalty, trust, and honesty. Indeed the ascription of meaning is a mainstay of such psychological tests as the Rorschach Inkblot Test and the Thematic Apperception Test. Facts are one thing, interpretation quite another: men in different seasons of their life may get up once in the night: in their youth it is to go home, later in life the same behaviour has a different reason.

\section{Foundations of the law}

Whether of not morality should be the basis of laws found expression in the Hart-Devlin debate began in the 1960s (Hart, Devlin)*. There the question was to what extent should morals intrude into the law? Plainly values do invest the law and its business corollaries, but because values vary in a multicultural society that is a problematical proposition. Here too, one may look for principles in order to resolve the puzzle. With respect to relationships there are two pillars. Once a pact is made the engagements must be maintained: keeping faith is paramount. A second and debatable point is that nobody may reasonably demand from others a behaviour, which s/he declines to undertake (again the 'Reciprocity Principle'). Here the issue is, should one refuse to fulfil the engagements held towards someone who fails to fulfil his own, or is the honour principle inviolable?

One of the bulwarks of freedom is that of the rule of law: really that should read 'just laws'. The concept of equality before the law, its universal application, and its regenerative nature, are essential features. The judicial system must work broadly since it is the only instrument available to the citizens in order to require conformance to the rules. Indeed, good governance resides in something more important and complex than mere stability of a government: it not only resides in the substance of the decisions but also in the ability to design and implement really adequate structures. Moreover, 'good governance' and effectiveness rest not only on results, but also on their cost and the way it is shared. Sorting out doubtful issues means making a choice - albeit risky. We have to decide what risks we accept.

Legal framing bodies aim to produce precise rules of unambiguity, apt to regulate a never-ending record of cases. In doing so it may well create complexity, and a capacity for 'loopholing' - finding creative business ways of subverting the law's intention. When it comes to drafting laws the maximum acceptable degree of simplification may be preferred. Regulation must show the mark of simplicity and evenness, so that all the citizens may easily know what behaviour they are required to embrace, and abide by. Simple rules are also easier to assess as for their substance and implementation. In other words the more technical the law the greater the opportunity for subversion.

People may abide by obligations only if and when those are realistic. When they are not, they provide a robust moral alibi to those, who are willing to circumvent them. Letting somebody contingently evade abiding by a rule means granting him an unfair advantage upon those, who abide by it. If this is allowed, it makes deviance appear as tolerated, and somehow legitimised. Such a gap opens room for some degree of profitable deviance. The deviant group will benefit of the other people's 'moral' (i.e. 'abiding') conduct, under the mere condition of paying attention to maintaining its opportunistic behaviour under the level of social harm that would justify stricter enforcement. Under particular circumstances a social 'elite' invested of decisional power may even find it convenient to back such behaviour, if it may secure specific advantage in terms of economic or political dominance of the group. From this emerges the principle that 'Rules, in both formal and substantial observance, enjoin equality'.

In this context the use of hypocrisy is worthy of comment. The basis of hypocrisy is to espouse one value and act on another (do as I say, not do as I do). A good international example is that the UN commitment to democracy. The Security Council has the right to veto any decision, hardly a 
democratic principle: further; it is comprised of members who lecture countries on human rights issues where a number of member states represent tyrants and dictators.

\section{Criteria for assessment}

The principles we have captured so far, provided that they are respected, are complementary and synergistic. Simplicity in rules, transparency in behaviour, functionality in interest structure design, equality in compliance, legitimacy in exerting power, warranty of equilibrium and social control reinforce themselves and grow with each other. The criteria for assessment cannot be simply the fact that a devised goal has been achieved: the method is not necessarily good just because the result was achieved. 'The end justifies the means' is the basis of most manipulations. The measure of success is inadequate because it tends to measure costs and benefits only from the viewpoint of those who stand to benefit, and does not necessarily consider the costs that others pay.

Here one must ask how can one be assured that a particular goal has been achieved? The answer must lie in majority approval. The dilemma here is that the majority may be mistaken in terms of human autonomy and of higher order principles: this is the reason of the search for principles sketched above. One additional useful guide may be the 30 precepts of the UN Declaration of Human Rights: a document of unprecedented persuasion. It is a pity that it has no corresponding statement of Human Obligations. With respect to business the UN Declarations has little to say: its contributions are indirect. For example it rightly espouses the dominance of law, of freedom of international movement. In particular Article 23 holds that everyone has the right to work (but, curiously, no obligations to do so).

Also critical criterion measures are those of time: short-term and the long-term effects may be at substantial variance. In various criminological studies it has been shown that what appears to be a benefit becomes, in the longer term, a detrimental intervention. That point is exemplified in the longer-term strategic planning of major multinational corporations.

We have already observed that the range of time taken into consideration by decision-makers is relatively short, given their pressing need to take further steps, mostly in order to maintain their power. That point applies, a fortiori, strongly to politicians (not to statesmen but even more strongly so for political party hacks). The criterion of social rather than personal success requires looking for longer time solutions. Indeed, the problems we face in the present time demand long-term answers. These may not particularly benefit those who will have to give them. But if they fail, this could make the planet unfit to live in for generations. It is, therefore, crucial that those who are appointed to lead the change are able to look in distance and to wait a long time for their reward, or accept that lesser prize that those who sow may not be around to see the harvest.

As those who fight for a socially desirable end know well, targeting difficult and durable goals requires being able to give up shortcuts or apparent and showy success: they must maintain their commitment with tenacity, and independently from the immediate reward.

\section{Conclusion}

A community exists because its members are acknowledged to hold common ends. Millennia of history have made these ends so obvious that they are often unconscious, rarely assessed, and sometimes ignored. Revitalising their awareness and common sharing is the base of the renewal of a true community. Starting from this initial step, the task inheres in putting these ends in order of priority, and developing mechanisms that may generate the best possible level of achievement watching lest rhetoric doesn't spoil, distort or manipulate. This applies from the larger political perspective, to business, and to personal development.

The contribution of this paper is twofold: to assert the point that the distressing rate of change may be ameliorated by confronting the issues; the second point is that the explication of principles is a substantial aid to guiding towards the kind of organisation that we want. In these processes it is 
counterproductive to leave human values out of consideration, since those values are exactly what makes engaging in action so worthy. It is better to acknowledge them explicitly, assessing their consistency and their actual sharing, understanding, and accepting their consequences. A vital society, a business, a governance issue, or a personality, cannot be but a fair one.

\section{References}

Bouma G (1998). Distinguishing institutions and organisations in social change. Journal of sociology. $34(3)$

Cottrell F (2009). Energy and society. Bloomington, Indiana: Author Press

Devlin P 1965. The enforcement of morals. London: Oxford UP

Donolo C (2001). Disordine. Roma: Donzelli

Ferguson Y H \& Mansbach R W (2004). Remapping global politics: history's revenge and future shock. Cambridge: Cambridge UP

Gini Index (after the Italian statistician Corrado Gini). en.wikipedia.org/gini_coefficient

Hart H L A (1987). Issues in contemporary legal philosophy. Oxford: Clarendon Press

Hart, H L A (1963). Law, liberty, and morality. London: Oxford UP

Peter L J \& Hull R (1969). The Peter Principle: why things always go wrong. NY: William Morrow \& Co.

Lever-Tracy C (2008). Global warming and sociology. Current sociology. 66 (3) 445-466

Pigou A C (1943).The classical stationary state. Economic journal. 53 210/211 202-2011

Pinker S (2011). The bettpeterer angels of our nature: the decline of violence in history and its causes. Harmondsworth: Penguin

Toffler A (1971). Future shock. London: Pan Books 
